\title{
Café e petróleo: um paralelo histórico
}

\author{
Hildete Pereira de Melo ${ }^{1}$ \\ Adilson de Oliveira ${ }^{2}$
}

\begin{abstract}
Resumo
O café, "ouro verde" do comércio exterior do século XIX, foi determinante no primeiro ciclo de forte expansão da economia fluminense. 0 petróleo, o "ouro negro" do século XX, sugere um novo período de forte expansão para a economia do Rio de Janeiro. 0 paralelo entre estas duas commodities é discutido com o objetivo de analisar a sustentabilidade do desenvolvimento da economia fluminense. Os efeitos de encadeamentos (linkages) propostos por Hirschmann são utilizados como abordagem analítica para avaliar esses dois momentos da economia do Rio de Janeiro. 0 café marcou o desenvolvimento regional, seus efeitos ficaram limitados à economia da cidade-porto; 0 interior fluminense permaneceu pobre e estagnado. 0 petróleo oferece a oportunidade de um futuro distinto do passado cafeeiro. Para que isso ocorra, é fundamental uma política ativa das instâncias políticas fluminenses, que promova o encadeamento dos efeitos industrializantes locais da produção petrolífera.
\end{abstract}

Palavras-chave: Rio de Janeiro; desenvolvimento econômico; café; petróleo.

\begin{abstract}
Coffee, the "green" gold of global trade of the XIXth century, has been the main driver of the first cycle of robust economic growth of Rio de Janeiro. Oil, the "black" gold of the XX century, suggests that a new period of robust economic growth is being initiated in the XXIst century. This paper explores the analogy between these two historical periods, aiming to evaluate the economic sustainability of the Rio de Janeiro oil boom. The Hirschmann linkages effects are used as analytical tool to compare these two moments of the Rio de Janeiro economic history. During the coffee period, the linkage effects were limited to the city-harbor; the Rio de Janeiro hinterland remained stagnated and poor. Oil offers an opportunity for a different future. However, its positive linkage effects will happen if only the Rio de Janeiro political establishment develops active policies that promote the industrializing effects of its oil production.
\end{abstract}

Keywords: Rio de Janeiro; Economic Development; Coffee; Oil. e

\section{Introdução}

Historicamente, o espaço geopolítico fluminense sofreu significativas mudanças. Olhando para o século XX, seu território abrigou a Capital Federal até 1960, depois essa cidade transformou-se no estado da Guanabara e em 1975 juntaram-se os territórios carioca e fluminense, formando o estado do Rio de Janeiro. Essa separação institucional engendrou também diferenças marcantes entre os dois territórios. Nas terras cariocas foi construído um sólido tecido industrial e comercial muito superior ao interior fluminense, que, na maior parte do século XX, permaneceu pobre e estagnado.

$\mathrm{O}$ artigo faz um paralelo entre a pujança da economia cafeeira no século XIX, o "ouro verde" do comércio exterior naquele século, e a economia do petróleo, o "ouro negro" do século $\mathrm{XX}$, que sugere um período esplendoroso para a economia do Rio de Janeiro nas próximas décadas. De forma interessante, o Rio de Janeiro foi e é protagonista de dois significativos momentos da economia nacional: um como rei absoluto da economia primário-exportador no século XIX e outro com o primado do petróleo e gás no offshore no início do século XXI.

O paralelo entre estas duas commodities é discutido para analisar o desafio da sustentabilidade do desenvolvimento da economia do Rio de Janeiro. O fio condutor é a abor-

1 Hildete Pereira de Melo: Doutora em Economia (IE/UFRJ), professora associada da Faculdade de Economia da Universidade Federal Fluminense, editora da Revista Gênero/UFF. hildete43@gmail.com

2 Adilson de Oliveira: Doutor em Economia do Desenvolvimento (Université de Grenoble/França), professor titular do Instituto de Economia da Universidade Federal do Rio de Janeiro. adilson@ie.ufrj.br 
dagem dos efeitos de encadeamentos (linkages) propostos por Albert Hirschmann (1961) para avaliar por que algumas regiões permaneceram atrasadas no processo de desenvolvimento econômico mundial. Para este autor, o desenvolvimento econômico é um processo de diversificação das atividades econômicas em torno de uma base produtiva em que um produto líder pode ser determinante no seu crescimento. Essa interpretação, baseada nas exportações de um produto básico (staples), pode explicar o dinamismo induzido na economia pelo setor exportador que, permanecendo no circuito do capital, tem a capacidade de induzir investimentos tanto a jusante como a montante de sua cadeia produtiva. Utilizamos o enfoque hirschmaniano para revisitar o passado opulento do Rio de Janeiro no Império e compará-lo com o cenário oferecido pelo petróleo no século XXI.

O Rio de Janeiro cresceu ao longo do século XX sempre abaixo da média brasileira. Uma economia pouco dinâmica, mas com uma base econômica poderosa, a economia fluminense persistiu no segundo lugar no ranking do Produto Interno Bruto (PIB) nacional. $O$ fator determinante dessa resiliência econômica pode ser encontrado na expansão mercantil e industrial induzida pelas exportações de café. A fermentação portuária da cidade aliada às rendas geradas pela produção cafeeira e ao gasto do governo incrementou a demanda efetiva da economia brasileira e fluminense. Essa efervescência era gerada pelos investimentos cafeeiros realizados nas atividades de beneficiamentos, máquinas, implementos agrícolas, sacaria e construção de ferrovias e as receitas fiscais (Melo, 2003 e 1993).

O petróleo anuncia um período de expansão da economia fluminense com encadeamentos em moldes similares aos produzidos pelo café. Sua demanda de logística, equipamentos e serviços exercerá papel importante indutor da demanda efetiva para a economia brasileira e fluminense. No momento, vive-se a euforia do petróleo. Porém é fundamental compreender que, como no caso do café, a expansão petrolífera pode ser abortada com o esgotamento das reservas desse combustível existentes na costa fluminense. Para evitar esse futuro indesejável, é preciso adotar políticas que deem sustentabilidade ao desenvolvimento econômico fluminense, após o esgotamento das reservas petrolíferas. Aliás, essa é a razão central da cobrança dos royalties que devem ser destinados à construção das bases da economia fluminense para o após petróleo.

Este artigo relembra o papel da economia cafeeira no Rio de Janeiro como alerta para o risco de o boom petrolífero repetir o boom cafeeiro. $\mathrm{O}$ forte incremento programado para as exportações brasileiras indica que, preservado o nível de preço atual do barril de petróleo, esse combustível deverá se tornar o principal item da pauta de exportação brasileira na próxima década.

$\mathrm{O}$ artigo procura responder as seguintes perguntas: o Rio de Janeiro corre o risco de reviver com o petróleo no século XXI algo similar ao que aconteceu com o café no século XIX? Ou o petróleo é uma oportunidade para que a economia fluminense ressuscite o apogeu do passado imperial?

Na próxima seção, o artigo faz uma síntese dos efeitos de encadeamentos do café ao longo do Império até a crise de 1929, que destronou o café como principal item da pauta de exportação fluminense e brasileira. Em seguida, analisamos a janela de oportunidades aberta pela produção petrolífera para o Rio de Janeiro. O artigo sugere que, para evitar um novo período longo de estagnação após o boom petrolífero, o governo fluminense deve adotar uma política ativa de promoção do enraizamento na economia fluminense dos encadeamentos para trás da produção petrolífera.

\section{0 café}

A ocupação da Capitania do Rio de Janeiro foi lenta, passando de um entreposto militar e comercial de pau-brasil para a produção de açúcar, aguardente e farinha de mandioca. Esses produtos e seu comércio possibilitaram o povoamento da capitania do Recôncavo da Guanabara para o Sul (Angra dos Reis e Paraty) e para Norte na baixada campista. A descoberta de ouro e diamantes na Região dos Gerais transformou a vida da capitania. Seu porto tornou- se o principal centro exportador dos metais preciosos e abastecedor da zona mineradora: escravos, carne-seca, peles, açúcar, aguardente. 
O comércio impulsionou a organização de mercadores e tropeiros e promoveu a integração das terras do Centro-Sul. Mas era preciso controlar este comércio e o governo português transferiu a capital da Colônia para o Rio de Janeiro em 1763. O significado desse ato pode ser medido pelas palavras do seu primeiro Vice-Rei, o Conde da Cunha: "pelo que se vê esta cidade... pela sua situação e porto deve ser a cabeça do Brasil" (apud Melo, 1993).

O território fluminense teve e tem uma rica participação na construção do Brasil. Porta de entrada para a região aurífera e de pedras preciosas no século XVIII, a cidade do Rio de Janeiro foi transformada na Capital da Colônia para coibir o comércio ilegal de ouro e diamantes até que as guerras napoleônicas reescreveram a história da Colônia. A vinda da corte portuguesa em 1808 para as Terras do Além-Mar e seu estabelecimento na cidade do Rio de Janeiro mudaram essa história.

O impacto econômico, social e demográfico foi excepcional, gerando riquezas e transformando os costumes locais. A efervescência comercial promoveu uma maior monetização da economia, organizou a Praça do Comércio do Rio de Janeiro. Foi criada a Junta de Comércio, Agricultura, Fábricas e Navegação para fiscalizar as atividades mercantis e cobrar impostos. O regente D. João, ainda em 1809, promulgou uma política de incentivos para importações de máquinas e matérias-primas sem taxas, e isto possibilitou a instalação de vários empreendimentos industriais na cidade (Lobo, 1978).

No entanto, a riqueza da região, que tinha começado como entreposto comercial, aproveitando as excelentes condições portuárias da Baía da Guanabara (anteriormente denominada do Rio de Janeiro) e que foi transformada com a instalação na cidade da Corte portuguesa, sofreu novo impacto com a introdução da atividade cafeeira nas terras fluminenses.

Os experimentos cafeeiros nas terras do Convento dos Barbonos (atualmente o Quartel da Polícia Militar, situado na rua Evaristo da Veiga, Rio de Janeiro) foram o pontapé inicial para a difusão do café entre os nobres lusitanos e o início da sua lavoura nas terras brasileiras. O café espalhou-se pelas cercanias da Baía de Guanabara, substituindo os antigos canaviais da baixada e ganhou a serra, primeiro no caminho da Capitania de São Paulo, no vale do rio Paraíba do Sul, e depois subiu para as terras do centro e do norte fluminense.

A riqueza originada pela lavoura e comércio do café no século XIX consolidou a autoridade dos fazendeiros do Rio de Janeiro junto à burocracia portuguesa e depois a imperial. José Murilo de Carvalho (1988) e Leslie Betthell (1989) consideram que este fato foi um dos mais importantes suportes para a coesão do Império Brasileiro em torno da autoridade do Rio de Janeiro: as relações de amor e ódio entre a cidade-porto e o interior da Província/Estado exprimiam a expropriação pela elite mercantil da cidade do Rio de Janeiro do excedente produzido pela agricultura exportadora interiorana, esta tensão exacerbou-se a partir da edição do Ato Adicional de 1834, que separou institucionalmente a cidade do Rio de Janeiro (Município Neutro) da Província do Rio de Janeiro (Ferreira, 1991). Diferentemente dos engenhos de açúcar, que exigiam investimentos em moendas, tachos de cobre, carros, gados e escravaria, as fazendas de café, antes da Abolição da Escravidão, restringiam seu capital aos cafezais e aos escravos, a demanda efetiva gerada por esta mão de obra era limitada de poucos produtos de alimentação e vestuário atendidos localmente. Seguramente, o regime escravista restringiu o desenvolvimento econômico da economia fluminense, quando comparado aos efeitos desta pós-abolição para a economia paulista, embora o crescimento da demanda mundial por café tenha requerido a expansão da cafeicultura para novas terras, agora transportado pelos trilhos ferroviários e exigido beneficiamento dos grãos para exportação, o que ampliou as possibilidades dos efeitos de encadeamentos para a economia cafeeira fluminense (Simonsen, 1973 e Melo, 1993).

Assim, a abundância de terras e a política da Regência de conquistar os súditos doando terras (sesmarias) pelos sertões do Rio de Janeiro e das Gerais contribuíram para a expansão da lavoura cafeeira, que crescia de importância no comércio mundial. Milliet de Saint-Adolphe (1863:418) escreveu "entre todas as terras, o Brasil é a mais bem agricultada e hortada", e Sebastião Ferreira Soares (1860:203) escreveu "nenhuma das Províncias do Império iguala em riqueza e indústria à do Rio de Janeiro, que não só pela grande produção de café e açúcar, como pelo comércio externo há em todos os tempos de prosperar”. Em meados do século XIX, o café era responsável por mais de $40 \%$ das exportações brasileiras, seguido pelo açúcar (27\%). Do café embarcado pelo Porto do Rio de Janeiro, $79 \%$ procediam das terras da Província do Rio de Janeiro, o restante das terras mineiras (Melo, 1993:48). 
A riqueza propiciada pelo café pode ser observada no Censo Demográfico de 1872 e analisado por Buescu (1985), que agregou os rendimentos das terras cafeeiras (Município Neutro e das Províncias do Rio e Minas Gerais). A Tabela 1 mostra que essa região tinha a renda per capita mais elevada do Brasil. Essa constatação pode ser corroborada pela arrecadação de impostos considerando apenas o Município Neutro e a Província do Rio de Janeiro: estes eram responsáveis por 52,26\% da arrecadação geral do Império (Soares, 1860).

Tabela 1: Renda per capita das regiões brasileiras -1872

$\begin{array}{lrr} & \text { Em Libras Esterlinas } & \text { Índice Brasil }=\mathbf{1 0 0} \\ \text { BRASIL } & 7,8 & 100 \\ \text { Norte } & 3,3 & 42 \\ \text { Nordeste } & 4,3 & 55 \\ \text { Pernanbuco } & 12,1 & 155 \\ \text { Leste } & 12,3 & 156 \\ \text { Bahia } & 4,0 & 51 \\ \text { Rio de Janeiro + Minas Gerais } & 17 & 218 \\ \text { Sul } & 3,1 & 40 \\ \text { São Paulo } & 3,0 & 38 \\ \text { Centro Oeste } & 0,5 & 7\end{array}$

Fonte: Buescu (1985:137)

\section{Encadeamentos para trás: ferrovias}

Os efeitos de encadeamentos para trás são originários do aumento da demanda por insumos pelo setor exportador. No entanto, a economia cafeeira teve frágeis relações intersetoriais. De acordo com a literatura, foi possível caracterizar esses linkages para o setor de transportes. A partir da década de 1840, a ascensão do café como o produto mais importante da pauta de exportações nacionais gerou a demanda de um sistema de escoamento da produção do interior do país para a costa. A construção da infraestrutura de transporte foi um dos maiores impactos que a renda cafeeira fomentou na economia do Rio de Janeiro.

Ainda no século XVIII, a economia mineira tinha exigido abertura de caminhos do Porto do Rio de Janeiro para o interior das Gerais. Foram abertos o Caminho do Comércio, a Estrada Nova e o Caminho da Serra, mas o percurso misto marítimo e terrestre continuava sendo o preferido (via Paraty, RJ). Mesmo a construção da Estrada União e Indústria, ligando Petrópolis a Juiz de Fora, numa extensão de 144 km, embora moderna para a época (1861), não foi suficiente para enfrentar a modernidade do transporte ferroviário. Esta estrada, orgulho da construção nacional rodoviária da primeira metade século XIX, já não resolvia a questão. Os caminhos das tropas de mulas provocavam enormes perdas aos fazendeiros. Urgia uma nova forma de transporte (o traçado desses caminhos foram os pontos de referência usados para o assentamento dos trilhos no futuro). Na Europa, o sistema de transporte estava sendo totalmente mudado pela introdução da máquina a vapor, que revolucionou os transportes marítimos e criou as ferrovias.

Na rica província cafeeira do Rio de Janeiro, entre 1852 e 1889, foram construídas dezenove ferrovias (Tabela 2), a sua maioria de pequeno porte. O grande empreendimento ferroviário tinha sido a construção da Estrada de Ferro Pedro II. Esta empresa gozava de intenso apoio da população: vencer a serra e correr para o interior, integrando essas terras com a Corte, representava o progresso e a modernidade. A dificuldade para sua organização, antes com capitais e engenharia dos ingleses (e que na década de 1860 tinha sido assumida pelo Estado Imperial), havia comovido a opinião pública nacional.

A pioneira das ferrovias nacionais havia sido a Estrada de Ferro Mauá, primeira ferrovia da América do Sul, que ligava um porto interiorano (Magé), no fundo da Baía do Rio de Janeiro, à raiz da serra de Petrópolis, em conexão com a Estrada União e Indústria. Assim, uma inovação tecnológica (em 1852) permitiu transportar o café do interior fluminense e mineiro para o Porto do Rio de Janeiro. Todavia, essa ferrovia estava distante da zona ca- 
feeira mais rica da Província (o Vale Sul do rio Paraíba do Sul), e a Estrada de Ferro Pedro II corria célere em sua direção. Em 1862, chegou à Barra do Piraí; em 1864 atingiu Porto Novo do Cunha (MG) e em 1866 alcançou Cachoeira (SP). A viabilidade da rede ferroviária dependia diretamente da quantidade de café transportada, e essa linha cortava a maior zona produtora de café do mundo - Vale Sul do rio Paraíba do Sul.

Tabela 2: Malha ferroviária do Município Neutro e do Rio de Janeiro - 1885

\begin{tabular}{|c|c|c|c|}
\hline Ferrovias & $\begin{array}{l}\text { Extensão } \\
(\mathbf{K m})\end{array}$ & $\begin{array}{l}\text { Capital (em } \\
\text { contos de Réis) }\end{array}$ & $\begin{array}{l}\text { Regime de } \\
\text { propriedade }\end{array}$ \\
\hline \multicolumn{4}{|l|}{ Municipio Neutro } \\
\hline Pedro II & 832 & 952,453 & União \\
\hline Rio do Ouro & 69 & 1.165 & União \\
\hline Corcovado & 4 & 400 & Privada Naciona \\
\hline Northern & 71 & 2.000 & Estrangeira \\
\hline \multicolumn{4}{|l|}{ Rio de Janeiro } \\
\hline Grão Pará & 92 & 4.000 & Privada Nacional \\
\hline Cantagalo & 309 & 10.861 & Província \\
\hline Carangola & 188 & 6.000 & Privada Nacional \\
\hline Ramal Cantagalo & 86 & --- & Privada Naciona \\
\hline União Valenciana & 63 & 1.080 & Privada Nacional \\
\hline Macaé/Campos & 104 & 8.000 & Privada Nacional \\
\hline Sto Antônio Pádua & 93 & --- & Privada Nacional \\
\hline Sta Isabel Rio Preto & 75 & 3.800 & Privada Naciona \\
\hline Pirahyense & 56 & 3.000 & Privada Nacional \\
\hline Barão de Ararruama & 41 & 800 & Privada Nacional \\
\hline Campos/ S. Sebastião & 18 & 600 & Privada Nacional \\
\hline Comércio/Rio das Flores & 27 & 790 & Privada Naciona \\
\hline Resende/Áreas & 28 & 2.200 & Privada Nacional \\
\hline Bananalense & 12 & 810 & Privada Nacional \\
\hline São Fidelis & 15 & --- & Privada Nacional \\
\hline Vassourenses & 6 & --- & Privada Nacional \\
\hline Rio Boito/Jutanahyba & 9 & --- & Privada Naciona \\
\hline
\end{tabular}

Fonte: Pessoa JR (1886 Apud Melo, 2002)

Os fazendeiros de café entendiam que a sobrevivência no longo prazo dos negócios cafeeiros dependia das estradas de ferro e se organizaram para construir vários ramais que se conectavam à Estrada de Ferro Pedro II com o Porto do Rio de Janeiro. Essa ferrovia era o principal tronco ferroviário fluminense, conectando a cidade do Rio de Janeiro com São Paulo e Minas Gerais. Os pequenos ramais fluminenses formavam, em 1885, $225 \mathrm{~km}$ de linhas entrecortadas. Na sua maioria, esses ramais foram construídos com investimentos diretos dos próprios fazendeiros, com apoio do Governo Provincial e das municipalidades cafeeiras. Como indica a Tabela 2, o capital estrangeiro teve participação marginal nesse processo. Foi o capital agrário fluminense, secundado pelo Estado Imperial, que realizou esses investimentos na infraestrutura, essenciais à continuação da acumulação de capital na atividade cafeeira. ${ }^{3}$

O fim do tráfico negreiro em 1850 em parte explica o negócio ferroviário daquelas décadas. A proibição rompeu com as rotas negreiras, os preços dos escravos elevaram-se e o plantel escravo passou a ser precioso. ${ }^{4}$ Capitais alocados no tráfico negreiro foram internalizados na Província e na cidade do Rio de Janeiro. A chegada dos trilhos, além de substituir as tropas, introduziu as carroças de bois no transporte das fazendas para as estações ferroviárias. Estes eram mais econômicos, tanto na força animal, como em termos de pessoal empregado.

3 Sobre esta questão ver Melo (2002), Topik (1987), Graham (1973).

4 Não esquecer de que, no mesmo ano de 1850, também foi aprovada a Lei de Terras, que significará uma impor tante mudança no mercado de terras do Brasil e consolidará o poderio dos fazendeiros de café na ocupação de novas terras para expansão dos seus cafezais. 
O barateamento do transporte de café deu uma sobrevida especial à lavoura cafeeira no Vale Sul do rio Paraíba do Sul.

Como cultura itinerante, o café avançou pelas terras fluminenses e com ela seguiu os trilhos de ferro. O grande tronco da Pedro II avançava pelo sul. Os fazendeiros do planalto central e do Norte, aliados com os plantadores de cana de açúcar, construíram linhas nas suas respectivas regiões. Surgiram assim a Estrada de Ferro de Cantagalo, Estrada de Ferro de Carangola, Ramal de Cantagalo, Estrada de Ferro Macaé-Campos, Estrada de Ferro Santo Antônio de Pádua, Estrada de Ferro Barão de Araruama, Estrada de Ferro São Fidelis e a Campos a São Sebastião. Em 1898, algumas dessas ferrovias fluminenses e mineiras formaram a Leopoldina Railway de capital inglês num processo rumoroso de fusão. Havia assim um emaranhado de linhas ferroviárias de Niterói, capital da Província do Rio de Janeiro, para o rico planalto central e para a baixada campista.

Em meados de 1880, havia 719 km de linhas ferroviárias em tráfego. Construídas por iniciativas diversas dos proprietários locais, formando uma rede desigual e ineficiente, com bitolas e materiais rodantes diferentes, elas tinham altos custos de manutenção, má qualidade dos serviços e graves problemas financeiros. Essas linhas, que entravam pelas terras cafeeiras do Espírito Santo e de Minas Gerais, foram ferrovias construídas pelo capital agrário regional. Seus traçados expressavam os interesses de plantadores e comerciantes de café, que tinham como parâmetro a valorização do escoamento das exportações e não uma integração com o incipiente mercado doméstico de outros bens e serviços.

A crise do Encilhamento de 1890 precipitou a decadência da rede ferroviária fluminense. Ela levou à encampação pela Central do Brasil (antiga Pedro II) da maioria dos ramais conectados com sua linha e também à formação da Leopoldina Railway em 1898, com incorporação das ferrovias instaladas no planalto central e norte fluminense, mata mineira e capixaba. Essa crise resultou num processo de concentração empresarial com duas grandes companhias (uma pública e a outra privada) monopolizando o transporte regional.

A construção desse sistema ferroviário foi importante para o crescimento da economia regional porque contratou companhias construtoras locais para as obras e fomentou o surgimento de fabricantes locais de material de construção. Também permitiu a capacitação de engenheiros e de técnicos brasileiros na atividade gerencial. As ferrovias reforçaram o poder e a riqueza da elite plantadora, e a cidade-porto do Rio de Janeiro foi especialmente aquinhoada com abertura da hinterlândia na medida em que a rede ferroviária marchou para o interior.

No entanto, o processo de expansão ferroviária não estimulou o desenvolvimento da indústria metal-mecânica local. Todo o material usado nos trilhos e o material rodante eram importados; consertavam-se locomotivas, mas não se tentou fabricá-las no país. As oficinas de reparação geraram uma mão de obra especializada como operadores, mecânicos e torneiros essenciais para um futuro industrial. Porém essa mão de obra qualificada não encontrou outros setores da economia onde pudesse utilizar os conhecimentos adquiridos no setor ferroviário.

As ferrovias foram construídas como necessidade da acumulação de capital da economia cafeeira. Elas tiveram uma interferência direta e positiva na produtividade do trabalho vinculado à atividade cafeeira bem como no custo e na comercialização do café. A modernização da infraestrutura reduziu custos de transporte e mudou as relações comerciais no interior do Rio de Janeiro. Ela diminuiu o tempo de viagem e ofereceu mais segurança a passageiros e cargas, deslocando o grosso comércio do interior para a grande cidade do Rio de Janeiro. Ao aumentar a velocidade de circulação do capital e renovar as oportunidades de lucro na atividade cafeeira, as ferrovias possibilitaram a concentração da vida econômica e social na cidade do Rio de Janeiro, em detrimento do seu interior que, ao longo do século passado, permaneceu pobre e estagnado.

\section{Encadeamentos para frente: processamento e beneficiamento do café}

No caso do café, esses efeitos restringem-se ao processamento dos grãos nas operações de limpeza e seleção. O café, depois de colhido, era transportado para os terreiros das fazendas, onde começavam as operações de beneficiamento. Desde a extinção do tráfico negreiro, havia a discussão sobre a introdução de máquinas na etapa do beneficiamento para substituir tarefas relativamente simples que consistiam na separação de impurezas da 
colheita. Nas tarefas de descascar e despolpar os grãos de café, foram introduzidos equipamentos mecânicos desde 1860 .

Era também imprescindível que os terreiros fossem impermeáveis (de tijolo, pedra ou macadame) para a secagem dos grãos de café. O uso de despolpadores e a construção dos terreiros representaram investimentos significativos para os plantadores. Somente os grandes produtores podiam arcar com os custos de sua construção. Os despolpadores substituíam o antigo método de descascar café em grandes pilões, e o pioneiro foi o descascador "Concassor", de José Ribeiro da Silva, aperfeiçoado pelo próprio e intitulado de descascador "Congresso". Este descascador foi premiado na primeira exposição de café realizada no Brasil, em 1881.

Depois de despolpados e descascados, os grãos necessitavam ser limpos das impurezas. Surgiram os ventiladores e separadores, que evoluíram para a secadora mecânica de Taunay e Silva Telles. Os irmãos Hargreaves também apresentaram uma máquina completa para executar essas tarefas na Exposição de 1881. A documentação desta Exposição permite entender que havia interesse por estas inovações que promoveriam mudanças nos processos tradicionais da produção de café, mas estes eram instrumentos artesanais incapazes de competir com a indústria de máquinas inglesas que, já nos anos 1880, abasteciam a lavoura cafeeira. As máquinas Lidgerwood (debulhadora, joieradora e separadora), junto com os tradicionais engenhos de pilões, eram os instrumentos mais utilizados nas fazendas de café. Essa máquina representava $23 \%$ do mercado, os engenhos de pilões, $35 \%$; o restante correspondendo a $42 \%$ era pulverizado pelos construtores nacionais ou de outros fabricantes. Naquele ano de 1881 a pujança da cafeicultura fluminense é atestada pelo fato de que $50 \%$ destas máquinas estavam instaladas nas fazendas de café fluminense (Centro da Lavoura e do Comércio, 1882, $\mathrm{n}^{\circ} 5$ ).

Essa manufatura semiartesanal desenvolveu-se no Rio de Janeiro a partir da segunda metade do século XIX, mas o crescimento da lavoura cafeeira para as terras paulistas encaminhou a importação dessas máquinas como solução para esta questão. Restaram alguns fabricantes e Freitas Filho (1992) lista no último quartel do século XIX alguns fabricantes fluminenses: Frederico Vierling \& CIa, Van Erven \& Irmãos, Arens \& Irmãos, F.L. Hallier, Alegria \& Cia, Hargreaves Irmãos, Prince \& Aspinal, Correia da Rocha \& Cia, Cia Oficina de Mecânica Industrial, G.Taunay \& A.Telles, Manoel F. de Castro Nascimento.

\section{Efeitos de encadeamentos de demanda final: trabalho e urbanização}

A economia cafeeira fluminense foi organizada de sua implantação até a maturidade na base do trabalho escravo. A Abolição da Escravatura trouxe um problema de financiamento para o capital de giro das fazendas, que até então não necessitavam pagar regularmente sua mão de obra. A libertação dos escravos significou a perda do "capital" investido na compra de escravos e a necessidade de novos créditos para o empreendimento cafeeiro. A economia cafeeira fluminense seguiu as pegadas paulistas e mineiras com uma produção exportável de mais de 1,5 milhão de sacas de café, em média, nas primeiras décadas republicanas.

A literatura histórico-econômica sobre trabalho livre no Brasil concentra sua atenção sobre a imigração paulista. No Rio de Janeiro, onde já havia uma significativa densidade demográfica regional na Capital Federal, a expansão do trabalho livre foi centrada na absorção dos escravos libertos e na imigração. Esta foi significativa sobretudo para a cidade do Rio de Janeiro (20,6\%) e o Estado de São Paulo (18\%), que concentravam 38,6\% da população estrangeira que vivia no Brasil em 1920. A urbanização fluminense estava baseada nas atividades mercantis e, em segundo plano, pelo parque industrial; as primeiras eram puxadas pelas exportações e importações (quase 50\% das importações brasileiras que entravam no país eram pelo Porto do Rio de Janeiro), enquanto São Paulo era o locus privilegiado das atividades industriais. As atividades de serviço e comércio, adicionadas ao aparelho burocrático do Estado, faziam da cidade do Rio de Janeiro um polo atrativo para a força de trabalho, tanto nacional como imigrantes.

50 Censo Demográfico de 1920 (IBGE) mostra que os imigrantes por tugueses fizeram a diferença, sobretudo na Capital Federal (ex-Distrito Federal); 39,74\% desses imigrantes (433.557 pessoas) viviam nessa cidade (Melo e Marques, 2008). 


\section{Encadeamento externo: o comércio de café}

A comercialização do café baseava-se em três atores. O comissário, espécie de corretor ou comerciante geral, que representava os plantadores, despachava os suprimentos para as fazendas e transportava e armazenava a produção. $\mathrm{O}$ ensacador, que comprava e misturava os diversos tipos de café, ensacava e vendia o produto para as casas exportadoras. A modernização do café com as ferrovias e com a mão de obra livre provocou a eliminação dessas etapas de intermediação. As casas exportadoras assumiram paulatinamente a compra direta do café nas fazendas.

Essa estratégia das casas exportadoras gerou muita tensão, sobretudo porque havia uma grande presença de exportadores estrangeiros na comercialização. No Rio de Janeiro, os comissários tentaram resistir e em 1901 fundaram o Centro de Comércio do Café para impulsionar os negócios das casas comissárias, mas acabaram sucumbindo aos ditames do capital internacional, que passou a controlar esse mercado.

Em 1870, o Jornal do Comércio publicou uma relação com 100 grandes casas exportadoras de café e mais 90 que eram de pequeno porte na Praça do Rio de Janeiro: os dez maiores exportadores respondiam por $62 \%$ das vendas. Em 1918, a revista Brazilian Review afirmou que havia 137 casas exportadoras na praça cafeeira fluminense. Essas firmas atuavam tanto no Porto do Rio de Janeiro como no de Santos (SP) e tinham o controle total das vendas de café para o mercado mundial (Melo, 1993:194-195).

Não se pode deixar de enfatizar a importante função portuária da cidade do Rio de Janeiro no desenvolvimento da cafeicultura brasileira. Em 1870, o porto do Rio de Janeiro respondia por $25 \%$ de todo o comércio das províncias brasileiras (Topik, 1991). Essa tradição se acentua nas décadas seguintes: em 1920, 46\% do total dos produtos importados pelo Brasil passam pelo Porto do Rio de Janeiro (Melo, 1993:200). Cabe realçar também que a cidade do Rio de Janeiro era um importante centro financeiro, tanto pela economia cafeeira como pela presença do aparelho do Estado. Na década de 1890, a praça financeira do Rio de Janeiro detinha $2 / 3$ dos ativos bancários brasileiros e sediava a única Bolsa de Valores do país (Melo, 1993:200).

\section{Efeitos de encadeamentos fiscais}

Os impactos da renda cafeeira na organização do estado fluminense foram muito fortes. $\mathrm{O}$ acelerado crescimento do café entre 1830 e 1880 havia compelido o Estado a alocar recursos na construção de uma infraestrutura ferroviária essencial para a expansão das exportações de café. No Império, as receitas de impostos da União eram cerca de quatro vezes maiores que as receitas provinciais. Embora a República atenuasse essa concentração, as receitas da União superavam entre 40 a $50 \%$ as dos estados. Tanto no Império como na República, o comércio exterior era responsável por cerca de $70 \%$ das receitas fiscais.

A Constituição de 1891 separou a taxação oriunda do comércio internacional entre exportações e importações. As receitas das exportações passaram integralmente para o estado exportador, o que nas décadas seguintes beneficiou, sobretudo, a economia paulista, que vivenciou o auge exportador cafeeiro nas décadas subsequentes à Proclamação da República. A Província do Rio de Janeiro dependia do porto da cidade do Rio de Janeiro, outro ente federativo, para escoar suas exportações. Além do mais, ainda disputava com Minas Gerais alíquotas e taxas sobre as exportações de café para os portos regionais.

Com a divisão, em 1834, entre o Município Neutro do Rio de Janeiro e a Província do Rio de Janeiro, na República foi mantida a designação de Distrito Federal para a cidade do Rio de janeiro, o que implicou elevadas perdas de receitas fiscais para o restante do território fluminense. O Distrito Federal tinha um governo indicado pelo Governo Federal e orçamento próprio reforçado pela presença do aparelho burocrático da União em sua jurisdição. $O$ estado do Rio de Janeiro, mesmo sendo também um centro exportador, dependia do Porto do Rio de Janeiro para escoar sua riqueza, e a comercialização das exportações gerava uma efervescência mercantil e bancária fora dos limites estaduais.

O processo de desenvolvimento vivido pela economia fluminense de 1850 a 1920 se deveu à expansão da atividade cafeeira. $O$ crescimento das exportações de café possibilitou 0 desenvolvimento dos transportes, das cidades e permitiu que o processo de acumulação de 
capital se consubstanciasse em casas comerciais, bancos e nas pioneiras indústrias nacionais. As duas faces da economia cafeeira, agrária e comercial, geravam uma efervescência mercantil e financeira que extrapolou os limites regionais.

\section{Petróleo e o Pré-Sal: oportunidade histórica}

O petróleo emergiu como riqueza estadual a partir de 1974, quando as sondas da Petrobras encontraram óleo na costa fluminense, mais precisamente nas águas da Bacia de Campos. Naquele momento, o Rio de Janeiro passou a ser o centro de desenvolvimento nacional da mais importante commodity do século XX. O petróleo, o ouro negro, é o recurso energético em torno do qual se organiza o sistema energético da economia global. Fonte de energia fungível, o petróleo tem como principal vantagem não demandar investimentos elevados em redes de transporte inflexíveis. A economia mundial atualmente consome cerca de 90 milhões de barris/dia, e essa mercadoria gera um excedente de cerca de dois trilhões de dólares anuais (Sauer, 2011).

O petróleo só ganhou importância com a difusão do motor à explosão interna nas atividades econômicas no início do século XX. Desde então, o petróleo tem atuado como forte impulsionador da expansão da economia mundial, inicialmente nos EUA, onde esteve na origem da transformação da economia capitalista fomentada pelo fordismo. Na segunda metade do século XX, os efeitos industrializantes do petróleo passaram a se reproduzir em outras partes do planeta (Maddison, 1995).

Em 1922, a Argentina criou a primeira empresa pública (YPF Argentina), dando início à política de intervenção estatal como forma de apropriação da renda criada pelo petróleo. Esse exemplo foi seguido pelo México que, em 1938, que criou a Pemex, numa reação ao domínio do mercado pelas grandes companhias petrolíferas. No Brasil, a descoberta de petróleo em Lobato (1939), no interior da Bahia, deslanchou o debate quanto ao modelo institucional para a exploração do petróleo no país (Melo, Oliveira e Araújo, 1994). A campanha popular "O petróleo é nosso" agitou o Brasil do Norte ao Sul, culminando na criação da Petrobras pelo Congresso Nacional em outubro de 1953. A Constituição brasileira determina que os recursos de hidrocarbonetos (petróleo e gás natural) sejam propriedades da União, princípio consagrado desde a Constituição de 1934. Isto significa que esses recursos pertencem à sociedade como um todo, e os seus benefícios econômicos devem ser repartidos com a cidadania. A repartição da renda petroleira entre a sociedade e as empresas petroleiras acompanha a história do petróleo.

Na década de 1960, os principais países exportadores de petróleo fundaram a Organização dos Países Produtores de Petróleo (OPEP) para defender sua parcela da renda petrolífera. Graças à atuação da OPEP, os países em desenvolvimento exportadores de petróleo conseguiram aumentar significativamente sua parcela da renda petrolífera, exercendo controle sobre o processo de esgotamento de suas reservas. No entanto, esses países pouco fizeram para sedimentar uma base industrial local que permita dar sustentabilidade ao enriquecimento financeiro provocado pela produção de petróleo em seu território. Sem essa base industrial, esses países convivem com uma elite enriquecida e um povo empobrecido.

A sede da Petrobras está na cidade do Rio de Janeiro desde sua fundação. Foram as descobertas de petróleo na Bacia de Campos, em 1974, que colocaram o Rio de Janeiro no cerne da indústria do petróleo brasileira. O Rio de Janeiro deixou de ser apenas a sede da empresa para se tornar o principal centro produtor de hidrocarbonetos do país. Todavia, os efeitos de encadeamentos das atividades de refino de petróleo e distribuição de derivados tiveram impactos muito limitados na economia fluminense. Não houve preocupação do governo federal tampouco do governo estadual na estruturação de um parque fornecedor doméstico para o qual pudessem ser canalizados os efeitos industrializantes da produção petrolífera na plataforma continental fluminense.

A Petrobras e o governo federal tinham, naqueles anos, como meta principal, a busca da autossuficiência petrolífera para remover o gargalo externo que estrangulava o desenvolvimento econômico brasileiro. A descoberta dos reservatórios supergigantes do pré- sal ocorre em um contexto radicalmente distinto do existente no terceiro quartil do século passado. O Brasil não mais vive sob a espada de Dâmocles do estrangulamento externo. Mais ainda, 
o Brasil passará à situação de exportador significativo de petróleo, situação que lhe garante uma posição favorável na geopolítica global.

A produção de petróleo no pré-sal muda a escala da indústria brasileira do petróleo. Os reservatórios supergigantes de hidrocarbonetos das bacias de Campos e de Santos abrem ampla janela de oportunidades para a construção de um polo fornecedor de bens e serviços para a indústria do petróleo no Brasil, orientado para o suprimento de todo o Atlântico Sul (De Oliveira, 2008). Esse polo terá seu centro motor no Rio de Janeiro, porém necessariamente será articulado com a base industrial existente no país. De Oliveira e Melo (2015) chamam atenção para as dimensões e desafios dessa janela de oportunidades gerada pela exploração do petróleo no Rio de Janeiro e da urgência da sociedade fluminense construir uma política de desenvolvimento que assegure, para as próximas décadas, essa trajetória de crescimento sustentado para a economia fluminense.

Para o Rio de Janeiro, o desenvolvimento da produção no pré-sal oferece a perspectiva de reversão na trajetória de mancha industrial e de serviços subordinada à expansão da economia paulista. Atualmente, o pré-sal é o principal laboratório de inovações tecnológicas para o offshore global. As inovações tecnológicas desenvolvidas no Brasil serão utilizadas em todos os países da costa ocidental africana, onde a geologia é similar à brasileira. Como o café, a produção petrolífera no estado anuncia encadeamentos induzidos pela atividade petrolífera que, adequadamente administrados, podem enraizar na economia fluminense o cerne de um polo competitivo de fornecedores de bens e serviço para a indústria do petróleo de todos os países do Atlântico Sul.

Entre a descoberta de petróleo na Bacia de Campos (RJ) e a década de 1990, a economia brasileira viveu um período de grande turbulência. As mudanças na forma de intervenção do Estado na economia, a abertura comercial e a desregulamentação econômica reforçaram o caráter terciário da economia regional. Depois de sofrer os efeitos restritivos desses anos, os investimentos voltaram a fluir para a economia fluminense. Eles são mais visíveis na indústria naval, porém não menos importantes são os investimentos no setor automotivo, na siderurgia e na logística portuária. A economia do Rio de Janeiro vive na atualidade um renascimento que ainda não está profundamente consolidado.

A produção petrolífera no estado teve papel expressivo no ordenamento de suas contas ficais. O fluxo fiscal vinculado à produção petrolífera seguirá crescendo. Para evitar que a maldição do petróleo se abata sobre o Rio de Janeiro, é fundamental que esses recursos passem a ser canalizados para o desenvolvimento do parque fornecedor de bens e serviços no estado.

\section{Considerações finais}

Claro que o papel do petróleo na economia não pode ser assimilado ao papel do café. Aquele é o principal insumo das economias industriais modernas, enquanto o café foi, e continua sendo, uma commodity marginal na economia global. No entanto, o café viveu dias de glória com a popularização do seu consumo (Netto, 1959). Assim, como o café foi a base do desenvolvimento da economia fluminense no passado imperial, o petróleo desponta como a grande oportunidade para que o Rio de Janeiro dê um salto no seu processo de desenvolvimento econômico no alvorecer do século XXI.

Diferentemente do passado imperial, quando a economia fluminense era pouco monetizada, hoje o Rio de Janeiro conta com uma economia diversificada. Portanto, a economia fluminense está mais aparelhada para explorar os efeitos dos encadeamentos hirshmanianos do petróleo que são de natureza distinta dos observados no caso do café. Porém está presente o risco de, passado o boom da produção petrolífera, o Rio de Janeiro mergulhar novamente na estagnação, como ocorreu no boom cafeeiro. Para evitar que esse risco se torne realidade, é preciso uma política ativa das instâncias políticas fluminenses, que promova o encadeamento dos efeitos industrializantes locais da produção petrolífera, não se deixe embalar pelo otimismo ingênuo que delega a política petrolífera ao governo federal. 


\section{Referências bibliográficas}

BETHELL, Leslie. Brazil Empire and Republic 1822-

1930. Cambridge University Press: Inglaterra, 1989.

BRASIL, ANP, Agência Nacional de Petróleo, Gás Natural e Biocombustíveis. Anuário Estatístico, 2013;

BUESCU, M. Brasil: problemas econômicos e experiências históricas. Rio de Janeiro: Forense Universitária, 1985

CARVALHO, José Murilo. A Construcão da Ordem. Rio de Janeiro: IUPERJ/Vértice, 1988. CÉNTRO DA LAVOURA E DO COMÉRCIO. Breve Notícia sobre a Primeira Exposição de Café do Brasil. Rio de Janeiro: Typ. Lyt de Moreira, Maximino \& Cia., 1882

DE OLIVEIRA, Adilson (coord.). Indústria Para-Petrolifera Brasileira: Competitividade, Desafios e Oportunidades. Relatório preparado para o Programa de Mobilização da Indústria Nacional do Petróleo e do Gás Natural (Prominp), 2008.

$\therefore$ MELO, Hildete P. de. 0 papel do petróleo no desenvolvimento fluminense. In: OSÓRIO, M., MELO, L. M. de, VERSIANI, M. H., WERNECK, M. L., (orgs.), Uma Agenda para o Rio de Janeiro - Estratégias e Políticas

Públicas para o Desenvolvimento Econômico. Rio de Janeiro: FGV Editora, 2015.

FERREIRA, Marieta Morais. Em busca da Idade de Ouro: as elites fluminenses na Primeira República (18891930). Tese de Doutoramento. Niterói: ICHF/UFF, 1991.

FIRJAN, Federação das Indústrias do Rio de Janeiro. Decisão Rio - Investimentos 2012-2014. Disponível em: www. firjan.org.br, acesso em abril e maio de 2014.

FREITAS FILHO, Almir P. A Tecnologia Agrícola e a Exposicão Nacional de 1881. Revista Latino-Americana de História da Ciência e Tecnologia (QUIPU), México, enero/ abril de 1992. GRAHAM, Richard. Grã-Bretanha e o início da modernização no Brasil 1850-1914. São Paulo: Editora Brasiliense, 1973.

\section{HIRSCHMANN, A. Estratégia do Desenvolvimento}

Econômico. Rio de Janeiro: Editora Fundo de Cultura, 1961.

JORNAL VALOR ECONÔMICO, 23 de abril de 2014.

LIMA, Paulo César Ribeiro. PRÉ-SAL - 0 novo marco

legal e a capitalização da Petrobras. Rio de Janeiro:

Synergia Editora, 2011.

LOBO, Eulália M., L. História do Rio de Janeiro (do Capital Comercial ao Capital Industrial e Financeiro). Rio de Janeiro: IBMEC, 1978.

MADDISON, Angus. L’Économie Mondiale: 1822-1992.
OCDE, 1995.

MELO, Hildete Pereira de. O Café e a Economia do Rio de Janeiro - 1888/1920. Tese de Doutoramento. Instituto de Economia da Universidade Federal do Rio de Janeiro, 1993.

Ferrovias e Café: Rio de Janeiro e Minas Gerais 1850/1910. In: 20 ANOS DO SEMINÁRIO SOBRE A ECONOMIA MINEIRA - 1982-2002, coletânea de trabalhos, 1982-2000. Belo Horizonte, UFMG/FACE/Cedeplar, 2002.

Coffee and development of the Rio de Janeiro economy, 1888-1920. In: CLARENCE-SMITH, William Gervase; TOPIK, Steven (eds.), The global coffee in África, Ásia, and Latin- American, 1500-1989. England: Cambridge University Press, 2003.

.; DE OLIVEIRA, Adilson; ARAUJO, João Lizardo de. 0 sonho nacional: petróleo e eletricidade (1954-94). In: GOMES, Ângela de Castro (Org.), VARGAS e a Crise dos Anos 50. Rio de Janeiro: Editora da Fundação Getúlio Vargas, 1994.

.; MARQUES, Teresa C.de N. Imigrantes portugueses no Brasil, a partir dos recenseamentos populacionais do século XX: um estudo exploratório de gênero. Revista Gênero, Núcleo Transdisciplinar de Estudos de Gêneros (NUTEG), Universidade Federal Fluminense, Vol. 9, n. 1, $2^{\circ}$ sem. 2008.

MILLIET de Saint-Adolphe. Dicionário geográfico e descritivo do Império do Brasil. Paris, 1863. NETTO, Antônio Delfim. 0 problema do café no Brasil. Tese de livre docência. Faculdade de Economia e Administração, São Paulo: Universidade de São Paulo, 1959.

SAUER, I. Prefacio. In: LIMA, Paulo C., R. Pré-Sal - 0 novo marco legal e a capitalização da Petrobras. Rio de Janeiro: Synergia Editora, 2011.

SIMONSEN, Roberto, C. Evolução industrial do Brasil. São Paulo: Companhia Editora Nacional/USP, Brasiliana, Vol. 349, 1973.

SOARES, Sebastião Ferreira. Notas estatísticas sobre a produção agrícola e carestia dos gêneros no império do Brasil. Rio de Janeiro, 1860 / Edição IPEA/INPES, 1977.

TOPIK, Steven. A presença do Estado na economia política do Brasil de $\mathbf{1 8 8 9}$ a $\mathbf{1 9 3 0}$. Rio de Janeiro: Editora Recor, 1987.

Metrópoles macrocéfalas: uma comparação entre a primazia do Rio de Janeiro e a cidade do México entre 1800 e 1910. DADOS, Revista de Ciências Sociais, IUPERJ/Vértice, vol. 34, n. 1, 1991.

copyright (C)reative commons Araujo, Oliveira 